\title{
8
}
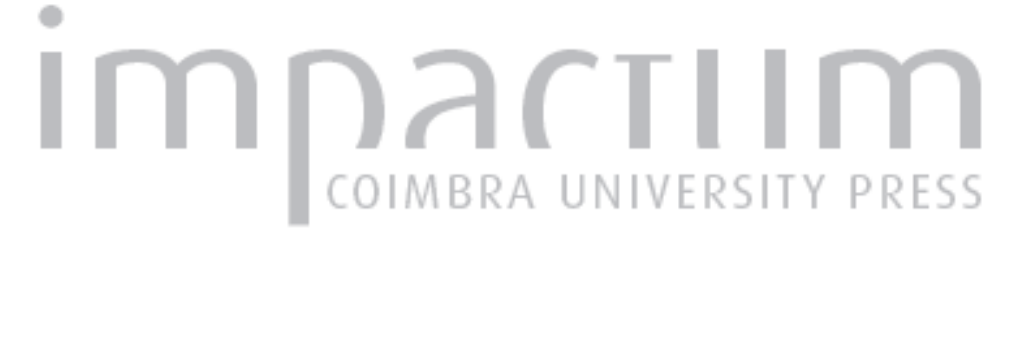

\section{Análise de susceptibilidade a alagamento na bacia hidrográfica do Riacho Fundo - Distrito Federal por meio de Sistemas de Informação Geográfica - SIG}
Autor(es):
Soares Neto, Gervásio Barbosa; Bayma, Adriana Panhol; Babinski Neto,
Stefano; Roig, Henrique Llacer; Menezes, Paulo Henrique Bretanha Junker
Publicado por: Associação Portuguesa de Riscos, Prevenção e Segurança; Imprensa da Universidade de Coimbra

URL persistente:

URI:http://hdl.handle.net/10316.2/41213

DOI:

DOI:https://doi.org/10.14195/1647-7723_24_6

Accessed : $\quad$ 26-Apr-2023 14:55:41

A navegação consulta e descarregamento dos títulos inseridos nas Bibliotecas Digitais UC Digitalis, UC Pombalina e UC Impactum, pressupõem a aceitação plena e sem reservas dos Termos e Condições de Uso destas Bibliotecas Digitais, disponíveis em https://digitalis.uc.pt/pt-pt/termos.

Conforme exposto nos referidos Termos e Condições de Uso, o descarregamento de títulos de acesso restrito requer uma licença válida de autorização devendo o utilizador aceder ao(s) documento(s) a partir de um endereço de IP da instituição detentora da supramencionada licença.

Ao utilizador é apenas permitido o descarregamento para uso pessoal, pelo que o emprego do(s) título(s) descarregado(s) para outro fim, designadamente comercial, carece de autorização do respetivo autor ou editor da obra.

Na medida em que todas as obras da UC Digitalis se encontram protegidas pelo Código do Direito de Autor e Direitos Conexos e demais legislação aplicável, toda a cópia, parcial ou total, deste documento, nos casos em que é legalmente admitida, deverá conter ou fazer-se acompanhar por este aviso. 


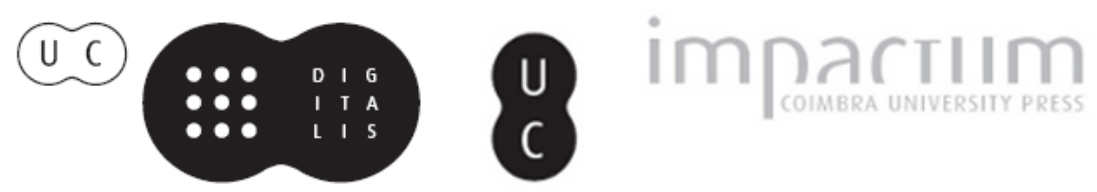

impactum.uc.pt digitalis.uc.pt 


\section{MULTIDISCIPLINARIDADE NA ANÁLISE DAS MANIFESTAÇÕES DE RISCO}

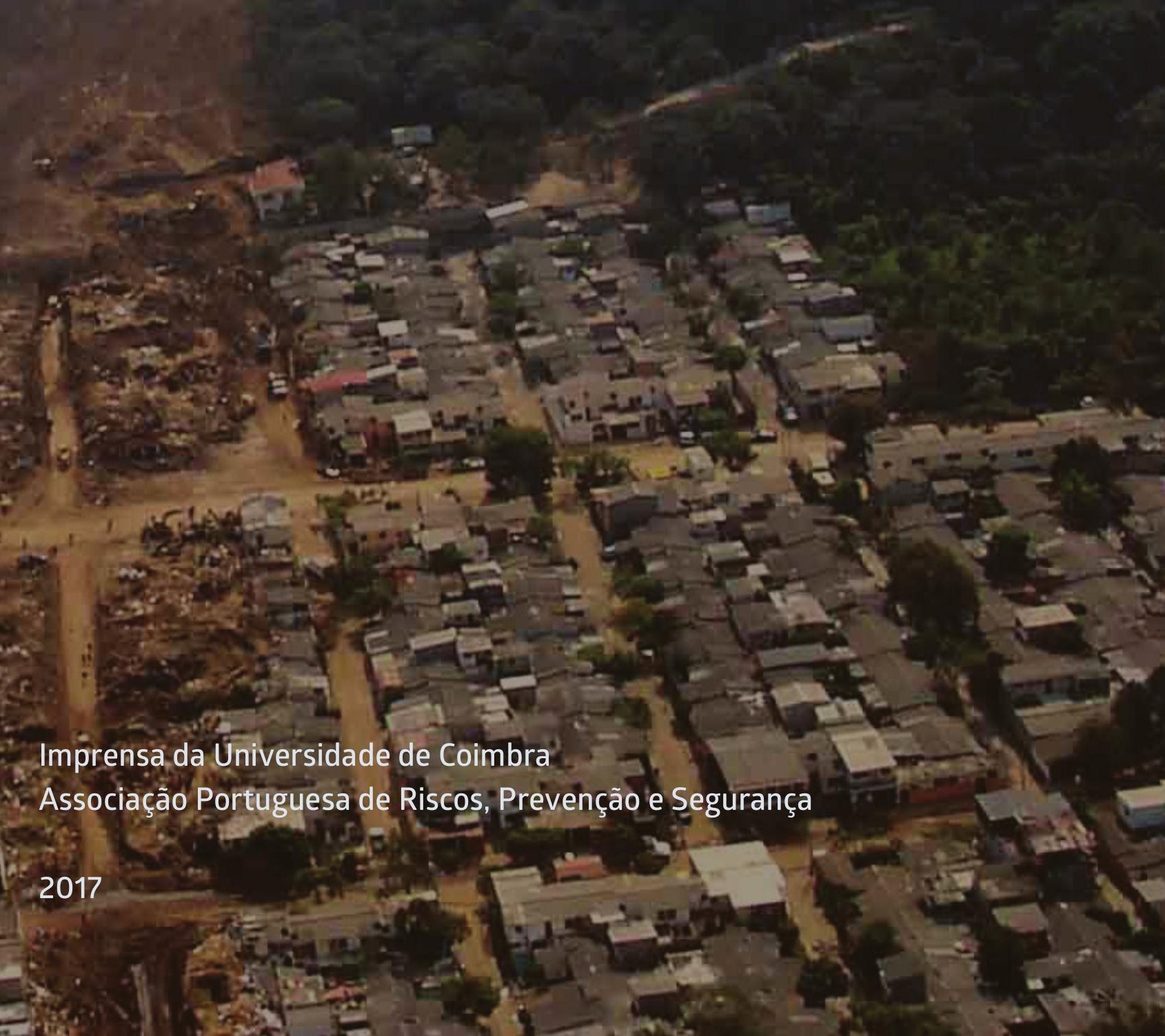




\section{ANÁLISE DE SUSCEPTIBILIDADE A ALAGAMENTO NA BACIA HIDROGRÁFICA DO RIACHO FUNDO - DISTRITO FEDERAL POR MEIO DE SISTEMAS DE INFORMAÇÃO GEOGRÁFICA - SIG*}

\section{SUSCEPTIBILITY ANALYSIS OF FLOODING AREAS IN THE HYDROGRAPHIC RIACHO FUNDO UNIT - FEDERAL DISTRICT THROUGH GEOGRAPHIC INFORMATION SYSTEMS - GIS}

\author{
Gervásio Barbosa Soares Neto \\ Instituto Federal de Brasília \\ gervasio.neto@etfbsb.edu.br \\ Adriana Panhol Bayma \\ Ministério do Meio Ambiente \\ Secretaria de Biodiversidade e Florestas \\ adriana.bayma@mma.gov.br
}

\author{
Stefano Babinski Neto \\ Universidade de Brasília \\ St.babinski@gmail.com \\ Henrique Llacer Roig \\ Universidade de Brasília / Instituto de Geociências \\ roig@unb.br \\ Paulo Henrique Bretanha Junker Menezes \\ Universidade Federal de Alfenas \\ paulo.menezes@unifal-mg.edu.br
}

\section{RESUMO}

Sistemas de Informação Geográfica (SIG) são considerados como uma vasta e poderosa ferramenta de suporte ao planejamento urbano. Nesse sentido, a análise de susceptibilidade a alagamentos de regiões por meio de SIG representa uma informação de alta importância para o poder público como suporte ao processo de zoneamento urbano, de delimitação de áreas de risco e para a alocação de recursos com finalidade corretiva e preventiva. Este estudo objetivou a determinação de áreas susceptíveis a alagamentos na Unidade Hidrográfica do Riacho Fundo.

Palavras-chave: Alagamento, susceptibilidade, SIG, Riacho Fundo.

\section{ABSTRACT}

Geographic Information Systems (GIS) are considered as a vast and powerful support tool for urban planning. In this sense, the susceptibility analysis of the flooding areas through SIG represents a highly important information for the government to support the zoning process, delimitation of risk areas and the allocation of resources with corrective and preventive purposes. This study aimed at determining areas susceptible to flooding in the Hydrographic Unit of Riacho Fundo.

Keywords: Flood, susceptibility, GIS, Riacho Fundo.

\section{RESUMEN}

Análisis a la susceptibilidad de inundación en la unidad hidrográfica del Riacho Fundo - Distrito Federal a través de los Sistemas de Información Geográfica - SIG - Los Sistemas de Información Geográfica (SIG) son considerados como una vasta y poderosa herramienta de apoyo para la planificación urbana. En este sentido, el análisis a la susceptibilidad de las áreas de inundación a través de SIG es una información muy importante para apoyar el gobierno en el proceso de zonificación, con la demarcación de las zonas de riesgo y la asignación de recursos con fines correctivos y preventivos. Este estudio tuvo como objetivo determinar las zonas de inundación susceptibles en la Unidad Hidrográfica del Riacho Fundo.

Palabras clave: Inundaciones, susceptibilidad, SIG , Riacho Fundo.

\section{RESUMÉ}

Analyse de la sensibilité aux inondations dans le bassin du Riacho Fundo (Distrito Federal) à l'aide des Systèmes d'Information Géographique - Les systèmes d'information géographique (SIG) sont considérés comme un outil indispensable et puissant dans la planification urbaine et l'étude de la vulnérabilité aux inondations. Il constitue pour les pouvoirs publics, une importante aide à la décision puisqu'il permet de faire un zonage urbain et de délimiter les zones à risque. Il permet aussi une meilleure amélioration de l'affection des ressources selon un schéma correctif ou préventif. Cette étude a pour objet la délimitation des zones soumises aux inondations dans l'Unidade Hidrográfica do Riacho Fundo.

Mots-clé: Inondation, suceptibilité, SIG, Riacho Fundo.

* O texto deste artigo corresponde a uma comunicação apresentada no I Seminário da Rede Incêndios-Solo e I Simpósio Ibero-Afro-Americano de Riscos, tendo sido submetido em 30-11-2015, sujeito a revisão por pares a 09-01-2016 e aceite para publicação em 27-03-2016.

Este artigo é parte integrante da Revista Territorium, $n .{ }^{\circ} 24,2017,{ }^{\circ}$ RIscos, ISSN: 0872-8941. 
Introdução

Dentre os fenômenos hidrológicos potencialmente destrutivos ao meio urbano, tais como enchentes e inundações, é abordado neste estudo aqueles resultantes de alagamentos.

Ao contrário dos dois primeiros citados que estão diretamente relacionados ao aumento do nível da água no leito do corpo hídrico decorrente de fortes pluviosidades, os alagamentos, segundo definição de Carvalho et al. (2007), são acumulações de água na superfície de um terreno qualquer, devido a características do meio físico, mau funcionamento de obras de drenagem e escoamento e/ou precipitações pluviométricas de alta intensidade em regiões não associadas à hidrografia da região.

Conforme descrito por Menezes et al. (2012), a bacia hidrográfica do Lago Paranoá, local onde se insere a área de estudo, passou por intenso processo de expansão urbana. Tal processo, em consonância com a lentidão do poder público, resultou na ocupação territorial desordenada, sem que tenha havido a análise prévia adequada de riscos ambientais e a delimitação de zonas de risco, tornando tal espaço susceptível aos fenômenos anteriormente citados e, principalmente, ao de alagamento.
O estudo de susceptibilidade a alagamentos na unidade hidrográfica do Riacho Fundo se justifica pela necessidade de análise de risco e pelos potenciais prejuízos sociais e econômicos que este tipo de catástrofe pode ocasionar, bem como na escassez de estudos relativos à temática exposta para a área. Ainda, tal estudo poderá servir de base ao poder público para proposição de ações que visem à redução de riscos, previsão de danos e prevenção de acidentes.

Ainda, ele objetiva identificar as áreas susceptíveis a alagamentos ao longo de toda a bacia hidrográfica do Riacho Fundo, Brasília - Distrito Federal, através do uso de ferramentas de SIG, com a definição de variáveis envolvidas no fenômeno, integração delas e a geração de mapa de susceptibilidade.

\section{Caracterização da Área}

\section{Localização}

Aárea escolhida (fig. 1) para o estudo de susceptibilidade é toda a unidade hidrográfica do Riacho Fundo, localizada na bacia hidrográfica do Lago Paranoá, na região centro-oeste do DF. Sua descrição é detalhada no título "Hidrografia"

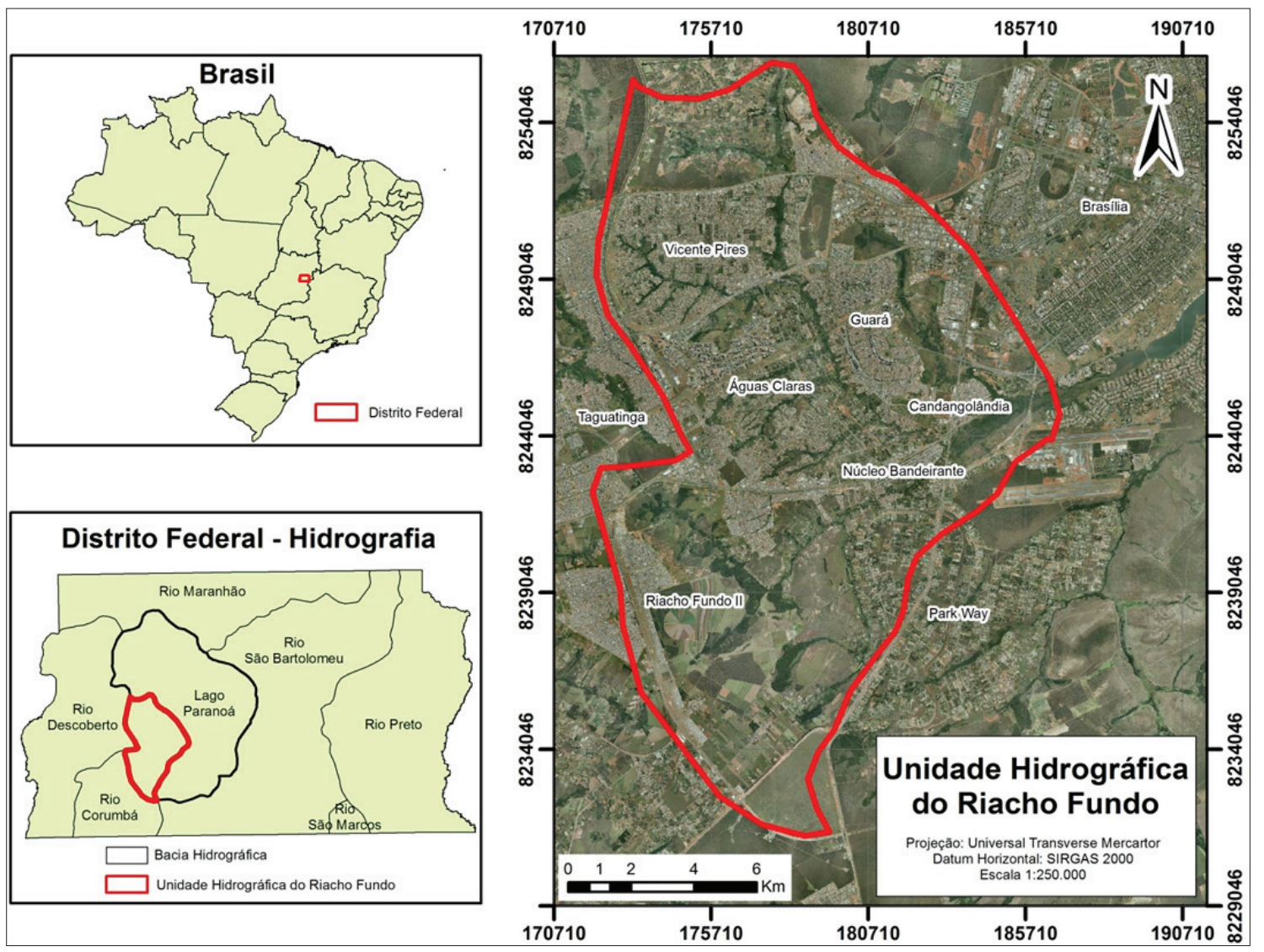

Fig. 1 - Localização da Unidade Hidrográfica do Riacho Fundo.

Fig. 1 - Hydrographic Unit location of Riacho Fundo. 
Tal figura foi elaborada tomando como base o mosaico aerofotogramétrico fornecido pela TERRACAP - Companhia Imobiliária de Brasília, SICAD 1:5.000 de 2013.

Clima

Segundo classificação climática de Koppen, a área de estudo abrange o tipo climático Tropical de Altitude, sendo dividida em duas classes climáticas: Clima subtropical úmido com inverno seco e verão quente (Cwa) e Clima subtropical de altitude com inverno seco e verão ameno (Cwb).

Relativo à pluviosidade, Nimer (1979 apud Ramalho, 2003) menciona regimes pluviométricos entre 1500 e $1750 \mathrm{~mm}$ anuais para o Distrito Federal, com mais de $70 \%$ das chuvas anuais acumuladas precipitando entre os meses de novembro a março, comportamento ratificado pelo INMET (1992).

Solo

Conforme Embrapa (1978), a área de estudo apresenta 6 classes de solo e outras duas classes; uma definida como área urbana, ocupada previamente à realização do levantamento, e a outra como corpos hídricos.
As 6 classes de solo encontradas na área de estudo, juntamente com suas principais características, são apresentadas no quadro abaixo.

Geologia

Freitas-Silva \& Campos (1998) definiram a geologia da região como composta por rochas metassedimentares dos grupos Canastra (no DF, clorita e sericita filitos e subordinadamente calcifilitos, filitos carbonosos, quartzitos e mármores finos), Paranoá (rochas metapsamo-pelíticas e cabornatadas), Araxá (muscovita xistos, clorita-quartzo xistos, muscovita-granada xistos e raras lentes de quartzitos micáceos) e Bambuí (metassiltitos, metassiltitos argilosos, metargilitos e raras intercalações de arcóseos).

\section{Geomorfologia}

Novaes Pinto (1986, 1987, 1994) caracterizou a paisagem do DF em 13 unidades geomorfológicas, que por suas similaridades morfológicas se agrupam em três grandes macrounidades típicas da região de Cerrado, sendo elas: Região de Chapada, Área de Dissecação Intermediária e Região Dissecada de Vale.

QUADRo I - Classes de solos existentes na área em estudo e suas principais características.

$T_{A B L E} I$ - Existing soils classes in the study area and its main features.

\begin{tabular}{|c|c|}
\hline Classe & Característica \\
\hline $\begin{array}{l}\text { Argissolo } \\
\text { (Vermelho } \\
\text { e vermelho } \\
\text { amarelo) }\end{array}$ & $\begin{array}{l}\text { Aumento substancial no teor de argila com profundidade e/ou evidências de movimentação de } \\
\text { argila do horizonte A para o horizonte B na forma de cerosidade. Compreende solos minerais, não } \\
\text { hidromórficos, com horizonte B textural de cores avermelhadas (Embrapa 2004). } \\
\text { Apresentam baixa a média permeabilidade (Salomão \& Antunes, } 1998 \text { apud Batista, 2014), } \\
\text { com textura e profundidades variáveis e ocorrem em relevo ondulado ou fortemente ondulado } \\
\text { (Embrapa 2004). }\end{array}$ \\
\hline $\begin{array}{l}\text { Latossolos } \\
\text { (Vermelho } \\
\text { e vermelho } \\
\text { amarelo) }\end{array}$ & $\begin{array}{l}\text { Solos altamente intemperizados, resultantes da remoção de sílica e de bases trocáveis do } \\
\text { perfil. São solos minerais, não hidromórficos, profundos, apresentando horizonte B latossólico } \\
\text { (Embrapa 2004). } \\
\text { Podem ser excessivamente drenados, fortemente drenados e acentuadamente drenados, com alta } \\
\text { permeabilidade de água. Ocorrem em topografia plana a suavemente ondulada (Embrapa 2004). }\end{array}$ \\
\hline Cambissolo & $\begin{array}{l}\text { Solos com horizonte subsuperficial submetido a pouca alteração física e química, indicando baixo } \\
\text { grau de intemperização. Seu horizonte subsuperficial é denominado B incipiente. } \\
\text { Variam desde rasos a profundos, com estrutura e textura bastante variáveis. Estão associados a } \\
\text { relevos mais movimentados ondulados e forte ondulados (Embrapa 2004). }\end{array}$ \\
\hline Plintossolos* & $\begin{array}{l}\text { Solos minerais com séria restrição à percolação de água, encontrados em situaçães de alagamento } \\
\text { temporário e, portanto, escoamento lento. (Motta et al., 2003a apud Embrapa, 2004). } \\
\text { Apresentam horizonte de subsuperfície (horizonte plíntico) com manchas avermelhadas } \\
\text { distribuídas no perfil de aspecto variegado. São rasos e ocorrem em relevo plano e suave } \\
\text { ondulado, em áreas deprimidas (Embrapa 2004). }\end{array}$ \\
\hline $\begin{array}{l}\text { Hidromórficos } \\
\text { Indiscriminados** }\end{array}$ & $\begin{array}{l}\text { Solos agrupados pelas características de má drenagem e comumente acúmulo de matéria } \\
\text { orgânica má decomposta sobre uma camada acinzentada (gleizada) (Embrapa 2004). } \\
\text { Apresentam textura bastante variável ao longo do perfil e têm drenagem dos tipos: mal drenado } \\
\text { ou muito mal drenado. Ocupam geralmente as depressões da paisagem, sujeitas a inundações } \\
\text { (Embrapa 2004). }\end{array}$ \\
\hline
\end{tabular}

* “Inclui solos conhecidos como Laterita Hidromórfica (Adálmoli et al., 1986) e/ou Concrecionários Lateríticos (Resente et al., 1988)"(Embrapa 2004, p.13).

** Classe definida pela Embrapa (2004) como agrupamento de Gleissolos Háplicos, Gleissolos Melânicos e Espodossolos. 


\section{Hidrografia}

Acerca da hidrografia, o DF é subdividido em três grandes regiões hidrográficas, sendo elas a Bacia do Rio São Francisco, a Bacia do Rio Tocantins Araguaia e a Bacia do Rio Paraná. O local de estudo se insere na última e integra a bacia hidrográfica do Lago Paranoá, localizada na porção central do Distrito Federal e que ocupa uma área de 288,69 km² , segundo SEMARH (1999), atingindo um contingente populacional expressivo por situar, quase que inteiramente, diversas Regiões Administrativas - RA.

A unidade hidrográfica do Riacho Fundo, alvo deste estudo, localiza-se na região sudoeste da bacia do Lago Paranoá e tem ao total $217,88 \mathrm{~km}^{2}$. Tem como principais cursos d'água os córregos Vicente Pires e Guará, que são afluentes do córrego Riacho Fundo e que abastece o Lago Paranoá, corpo hídrico de grande importância social e ecológica na região de Brasília.

\section{Metodologia de Trabalho}

O procedimento metodológico para a confecção do estudo de áreas susceptíveis a alagamentos baseou-se nas seguintes etapas de trabalho:

- Definição da metodologia apropriada para a identificação de áreas susceptíveis a alagamentos;

- Aquisição materiais a serem utilizados: dados e bases cartográficas;

- Definição de variáveis participantes no processo e atribuição de relevância (peso) a elas;

- Confecção de mapas temáticos;

- Integração dos dados;

- Análise e discussão dos resultados obtidos.

A definiçãa da metodologia para a identificação de áreas susceptíveis a alagamentos se deu através da pesquisa e análise de trabalhos anteriormente elaborados com essa finalidade, em especial, monografias e teses de mestrado e doutorado, bem como em livros e artigos relacionados (Campana, 2001; Jacob, 2015; Amaral, 2009; Canholi, 2002; Canholi, 2005; Sausen e Lacruz, 2015).

\section{Método Utilizado}

A metodologia utilizada para a obtenção dos resultados propostos foi baseada na classificação espacial através do algoritmo de média ponderada, da definição de variáveis pertinentes e a valoração de suas importâncias para a ocorrência do fenômeno estudado, elaboração de mapas temáticos segundos os critérios definidos e integração entre os dados gerados através do algoritmo, permitindo assim, a análise e discussão dos resultados obtidos.
A integração dos dados através do método de classificação espacial por média ponderada é, segundo Eastman et al. (1995 apud Muller, 2012) a técnica mais utilizada em projetos que envolvam análise espacial.

Muller (2012), descreve o método como a inferência de pesos aos dados de entrada em função da importância destes para a hipótese sobre consideração, com a definição empírica de pesos e a soma ponderada dos planos de informação segundo sua importância relativa. Segundo Dias et al. (2005), o algoritmo classificador (média ponderada) é aplicado a uma estrutura de matrizes, no qual cada célula corresponde a uma unidade territorial, com a análise individual de pixel.

Conforme Xavier da Silva (2001 apud Muller, 2012) o somatório dos pesos dos planos de informações (variáveis) ao ser normalizado passa a ser expresso no intervalo de 0 a 1 , com a soma dos pesos significando a unidade. Para o presente trabalho, foram consideradas na avaliação as classes existentes em cada variável, com a atribuição empírica de valores conforme sua influência no evento estimado, com valores variando entre 1 a 5 , de acordo com o menor ou maior grau contribuição da classe ao processo de alagamento de áreas, respectivamente.

Tanto a integração dos dados quanto os processamentos anteriores foram realizados utilizando o pacote de ferramentas do $\operatorname{ArcGis} \circledast$ e extensões associadas.

\section{Variáveis Estudadas}

Relativo à definição de variáveis, foram considerados os componentes ambientais intrínsecos aos processos de alagamento de áreas, independentemente da precipitação incidente na área. A descrição e justificativa de cada variável e a definição de pesos às mesmas e as suas classes, são abordados nos subtítulos seguintes.

\section{Pedologia}

Dentre as diversas características e comportamentos que um solo pode apresentar, destacam-se para o presente estudo a capacidade de infiltração (permeabilidade), profundidade, textura e granulometria. Dependendo da combinação desses fatores, as águas pluviais apresentarão maior tendência a infiltração ou ao escoamento quanto entrar em contato com determinada classe.

A base de dados referente ao tema pedologia foi extraída de Embrapa (1978).

Considerando as características físicas genéricas de cada classe de solo encontrada na bibliografia consultada, especialmente aquelas já citadas, considerados os fatores de maior importância para a velocidade de infil- 


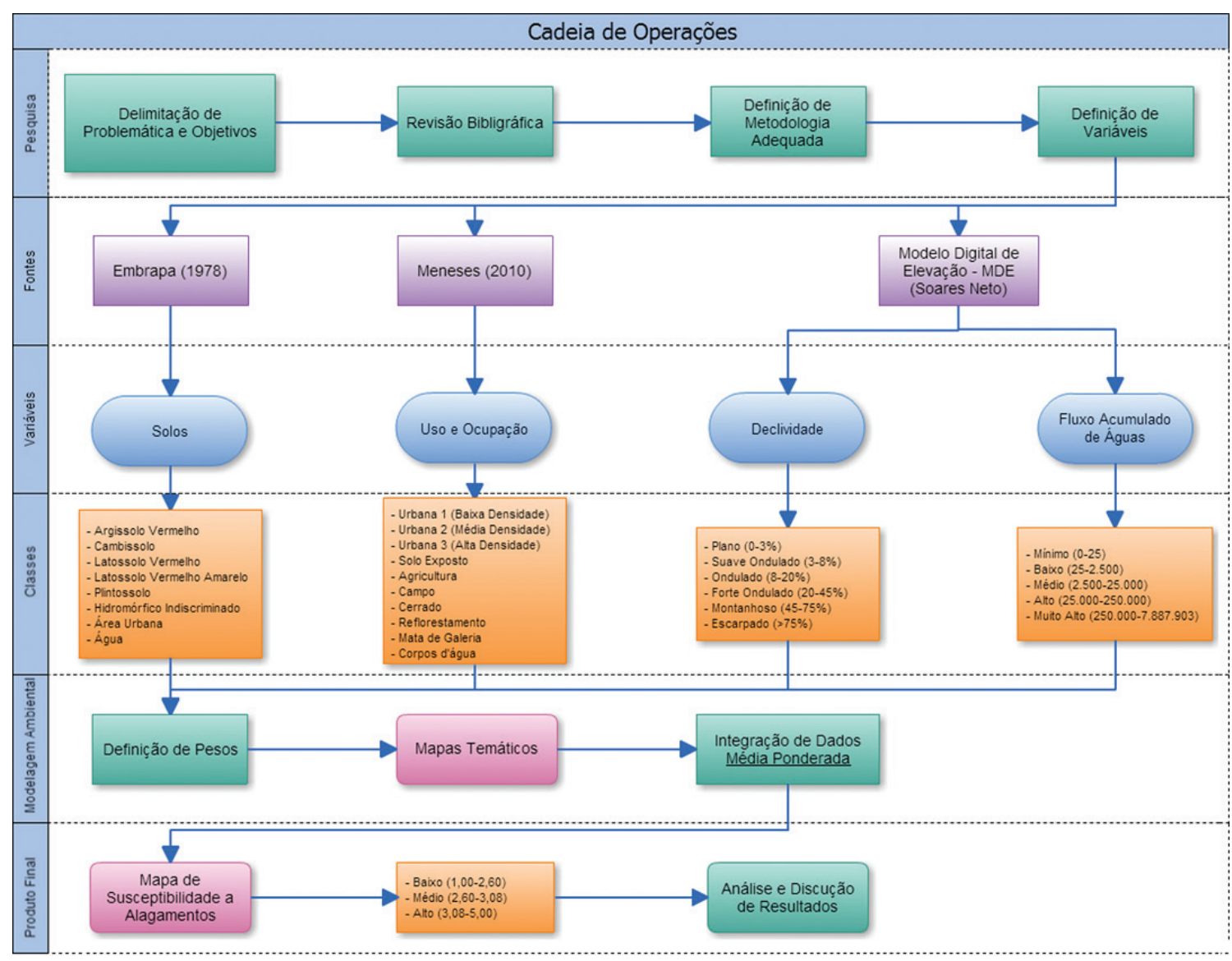

Fig. 2 - Fluxograma de atividades do estudo.

Fig. 2 - Flowchart of the study activities.

tração de águas, foram atribuídos os seguintes valores para cada classe (fig. 3 e QUADRo II).

Dentre as classes de solo encontradas na região por Embrapa (1978), destacam a Área Urbana e a Água que, para a metodologia proposta, foram atribuídos valores mínimos de interferência, uma vez que os mesmos já são considerados e valorados na variável Uso e Cobertura do Solo.

\section{Uso e Ocupação do Solo}

O uso e cobertura do solo está diretamente associada a permeabilidade da região, de acordo com a destinação da mesma. Neste caso, espera-se maior tendência a retenção e infiltração de águas pluviais em áreas de mata nativa e reflorestamento e ao escoamento em áreas com maior grau de pavimentação, como áreas urbanas por exemplo.

A base de dados do uso e ocupação do solo foi extraída de Menezes (2010), que data do ano de 2009 e foi feita com base na análise da imagem do sensor AVNIR-2, do satélite japonês ALOS, a qual foi georreferenciada utilizando a base cartográfica da CODEPLAM em escala 1:10.000 em sistema de projeção SICAD.

Segundo classificação adotada pelo mesmo, a área em estudo foi dividida em 10 classes, abrangendo as principais categorias de uso e ocupação que ocorrem no local. 0 peso dado a cada uma delas se deu em base no nível de impermeabilização e na propensão ao escoamento das águas pluviais (fig. 4 e QUADRo II).

\section{Declividade}

O critério de declividade está diretamente associado à propensão ao escoamento ou acúmulo de água de uma determinada região. Tem-se que áreas planas apresentam maior probabilidade de alagamentos pela menor velocidade de escoamento que áreas montanhosas e escarpadas, que resultam maior velocidade.

Tal dado foi gerado através do Modelo Digital de Elevação (MDE) do terreno, gerado pelo GDF (2010) em escala 1:10.000, com a separação de classes de declividade conforme importância para o tema escolhido (fig. 5 e QUADRO II). 
Acúmulo de Fluxo de Água

Tal variável está associada à declividade e conformação do terreno e é definida pela propensão da água a tomar determinado caminho ao longo do terreno, formando canais preferenciais de drenagem. Regiões identificadas como canais preferenciais de drenagem acumulam as águas pluviais locais e tendem a formar enxurradas.

Tal dado foi derivado dos dados de MDE e modelo de direção de fluxo de água. De acordo com o grau de acúmulo de fluxo, foram definidas 4 classes, as quais obtiveram pesos abaixo (fig. 6 e QUADRO II).

\section{Integração de Dados}

A integração dos dados se deu com a sobreposição das variáveis citadas e a aplicação do algoritmo de média ponderada, com vistas à identificação das áreas passíveis a alagamento.

Além dos pesos atribuídos às classes de cada variável, considerou-se também que cada uma delas apresenta graus de contribuição distintos para o fenômeno estudado, resultando assim na definição de pesos para cada uma destas, de forma a hierarquizar sua contribuição ao processo de alagamento.

Foram definidos os seguintes pesos para cada variável: 20\% para Solos, 25\% para Uso e Ocupação, 30\% para Declividade e $25 \%$ para Acúmulo de Fluxo de Água. No geral, considerou-se como semelhante a contribuição das classes Uso e Ocupação e Acúmulo de Fluxo de Água ao fenômeno, enquanto que a variável declividade apresentou peso maior por se considerar essencial ao processo de acúmulo de água e, de forma oposta, solos com menor peso, por se considerar que o mesmo recebe a influência das variáveis Declividade e Uso e Ocupação.

Por fim, a fórmula de suscetibilidade a alagamentos foi definida na Equação 1, abaixo:

Equação 1: “ $\left(0,20^{*}\right.$ Solos $)+\left(0.25^{*}\right.$ Uso e Ocupação $)+$ $\left(0,30^{*}\right.$ Declividade $)+\left(0,25^{*}\right.$ Acúmulo de Fluxo $) ”$

\section{Identificação de Áreas Susceptíveis a Alagamentos}

Através do cruzamento de dados e tomando como base o modelo proposto, foram identificadas as principais regiões susceptíveis ao processo de alagamento na unidade hidrográfica do Riacho Fundo. Foram definidas três classes de níveis de suscetibilidade: baixa, média e alta, conforme a propensão do terreno em acumular água. 0 resultado obtido é apresentado na fig. 7 .

Através do mapa gerado, criou-se o QuAdro III, com os resultados obtidos conforme a área ocupada e a percentagem da mesma.

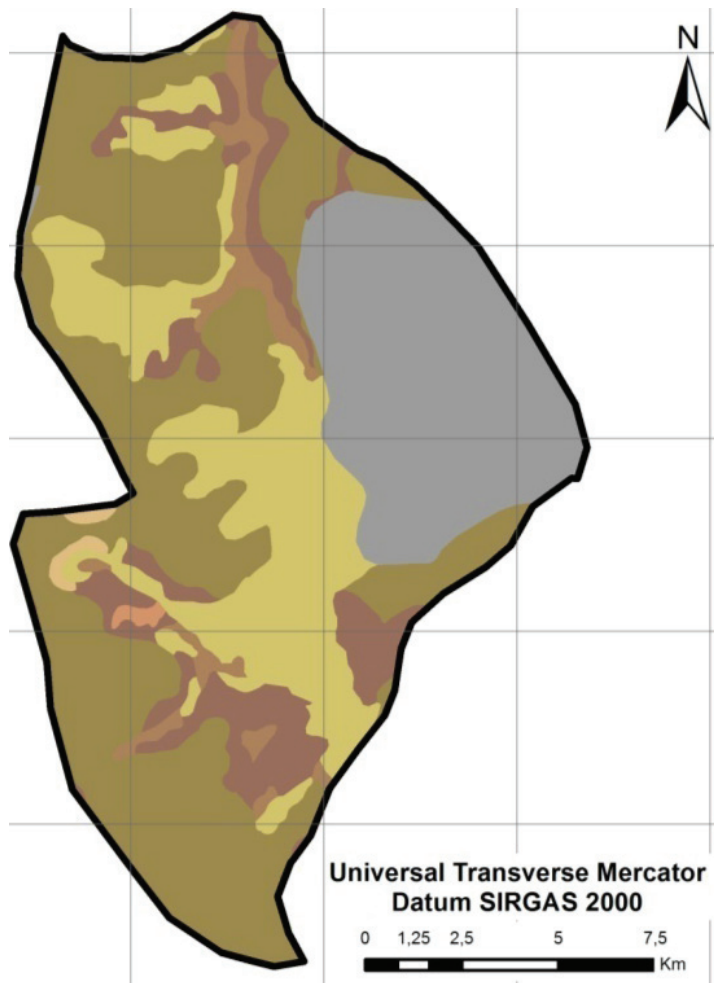

Fig. 3 - Classes de solos que ocorrem na área.

Fig. 3 - Class of soils occurring in the area.

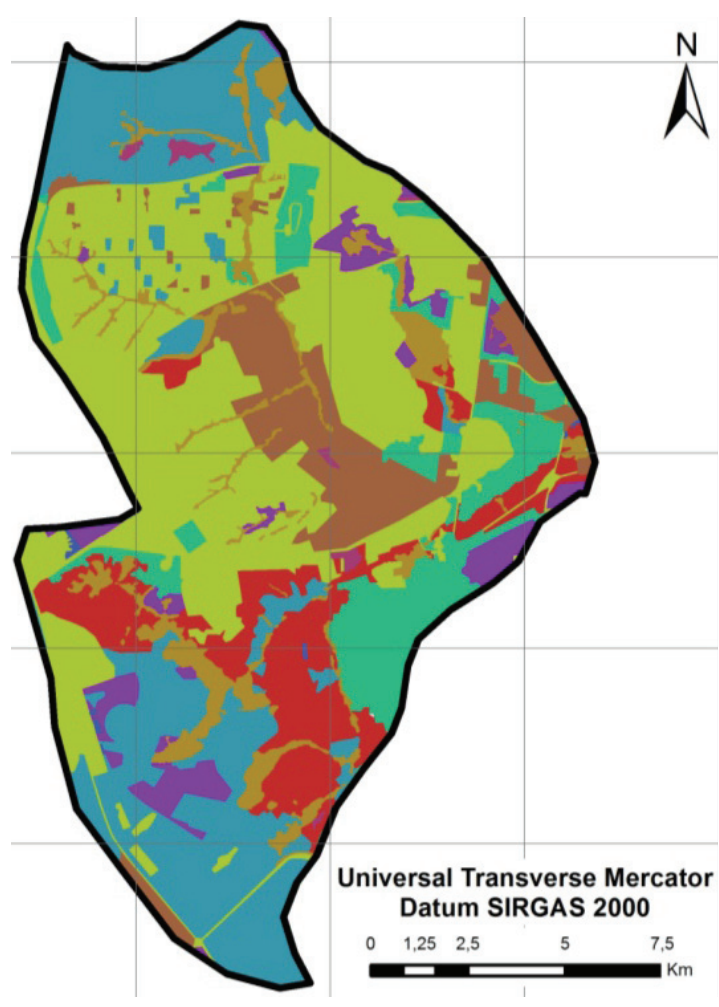

Fig. 4 - Classes de uso e ocupação do solo.

Fig. 4 - Use and occupation land classes. 


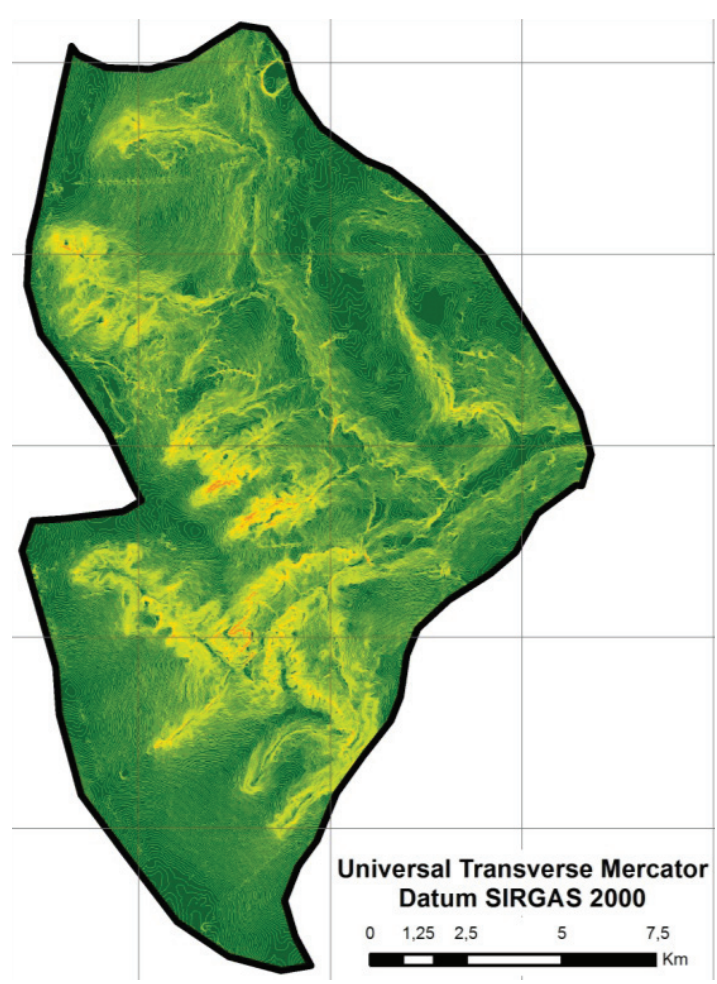

Fig. 5 - Classes de declividade do terreno. Fig. 5 - Land slope classes.

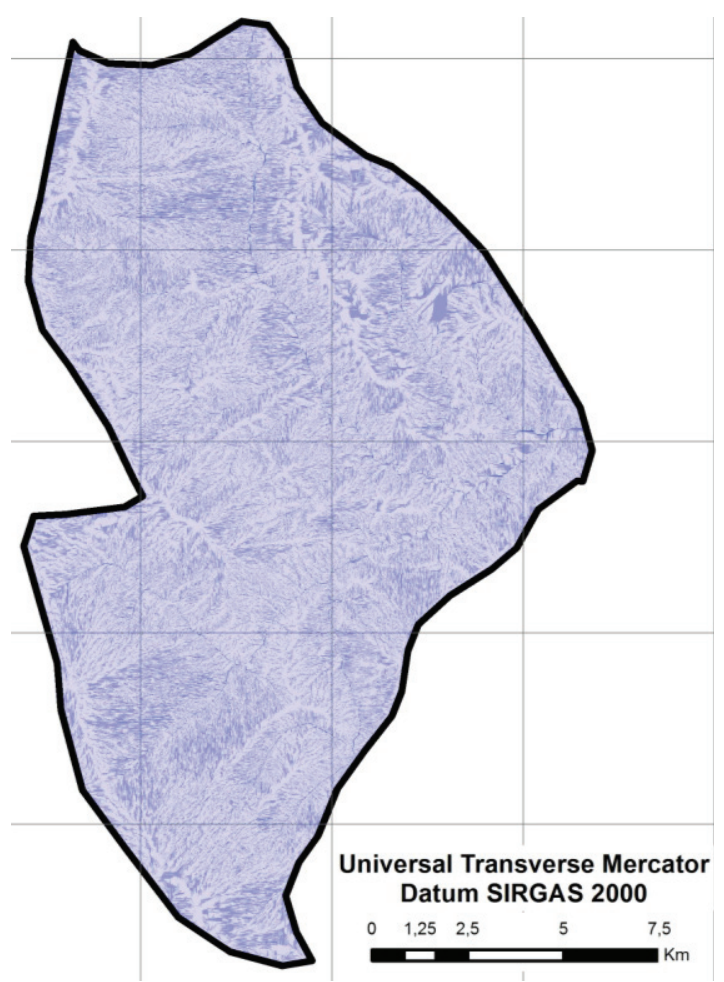

Fig. 6 - Classes de acúmulo de fluxo de água.

Fig. 6 - Water flow accumulation classes.
QUADRo II - Legenda das figuras e ponderação atribuída a cada uma das variáveis.

QUADRO II - Legend of the figures and weighting given to each of the variables.

\begin{tabular}{|c|c|c|}
\hline Figura 3 & Solos & Peso \\
\hline & Argissolo Vermelho & 3 \\
\hline & Cambissolo & 3 \\
\hline & Latossolo Vermelho & 2 \\
\hline & Latossolo Vermelho Amarelo & 2 \\
\hline & Plintossolo & 4 \\
\hline & Hidromórficos Indiscriminado & 5 \\
\hline & Área Urbana (1978) & 1 \\
\hline & Água & 1 \\
\hline
\end{tabular}

\begin{tabular}{|c|c|c|}
\hline Figura 4 & Uso e Ocupação & Peso \\
\hline & Urbana 1 - Baixa Densidade & 3 \\
\hline & Urbana 2 - Média Densidade & 4 \\
\hline & Urbana 3 -Alta Densidade & 5 \\
\hline Solo Exposto & 4 \\
\hline Agricultura & 3 \\
\hline Campo & 3 \\
\hline & Reflorestamento & 2 \\
\hline Mata de Galeria & 1 \\
\hline & Corpos d'água & 5 \\
\hline
\end{tabular}

\begin{tabular}{|c|c|c|c|}
\hline Figura 5 & Classe de Relevo $^{1}$ & $\begin{array}{c}\text { Declividade } \\
\text { (\%) }\end{array}$ & Peso \\
\hline & Plano & $0-3$ & 5 \\
\hline & Suave Ondulado & $3-8$ & 4 \\
\hline & Ondulado & $8-20$ & 3 \\
\hline & Forte Ondulado & $20-45$ & 2 \\
\hline & Montanhoso & $45-75$ & 1 \\
\hline & Escarpado & $>75$ & 1 \\
\hline
\end{tabular}

\begin{tabular}{|c|c|c|}
\hline Figura 6 & Acumulo de fluxo & Peso \\
\hline & Mínimo (0-25) & 1 \\
\hline & Baixo (25-2.500) & 2 \\
\hline & Médio (2.500-25.000) & 3 \\
\hline & Alto (25.000-250.000) & 4 \\
\hline & Muito Alto (250.000-7.887.903) & 5 \\
\hline
\end{tabular}

I EMPRESA BRASILEIRA DE PESQUISA AGROPECUÁRIA - EMBRAPA. Serviço Nacional de Levantamento e Conservação de Solos (Rio de Janeiro, RJ). Súmula da 10. Reunião Técnica de Levantamento de Solos. Rio de Janeiro, 1979. 83p. (EMBRAPASNLCS. Micelânea, 1). 
Conforme observado no quadro anterior, houve a predominância do grau de susceptibilidade da classe "Média"com 45,18\% de toda a área analisada, seguido da classe "Alta" e classe "Baixa", com 33,12\% e 21,69\% de área, respectivamente.

O modelo proposto aponta as áreas mais susceptíveis a processos de alagamento nas áreas urbanas, em especial, aquelas definidas na variável uso e ocupação do solo como "Urbana 3 - Alta Densidade". Tais áreas coincidem com os centros urbanos já consolidados, abrangendo os núcleos urbanos do Guará, Vicente Pires, Estrutural, Taguatinga e Riacho Fundo, ainda que elas se apresentem com solos da classe "Latossolo", considerado pela literatura como solos bem drenados.

Ainda relativo às áreas apontadas como de alta susceptibilidade, destaca-se o trecho existente na porção central da área de estudo. Ainda que a mesma

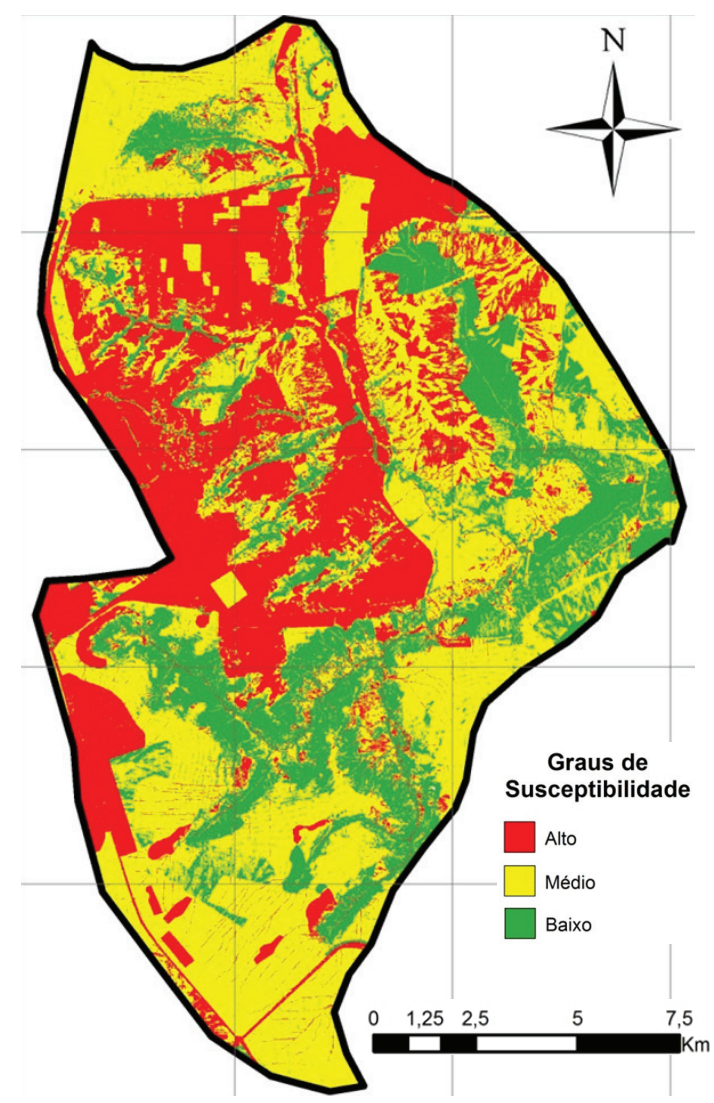

Fig. 7 - Susceptibilidade a alagamentos na unidade hidrográfica do Riacho Fundo.

Fig. 7 - Susceptibility to flooding in Hydrographic Unit of Riacho Fundo.

QUADRo III - Resultados da análise de susceptibilidade a alagamentos.

TABLE III - The flooding susceptibility test results.

\begin{tabular}{|c|c|c|}
\hline Graus de Susceptibilidade & Soma das Área & $\%$ \\
\hline Alta & $7.184,88$ & 33,12 \\
\hline Baixa & $4.705,09$ & 21,69 \\
\hline Média & $9.799,48$ & 45,18 \\
\hline
\end{tabular}

pertença à classe "Urbana 2 - Média Densidade", de impermeabilização mediana, com a presença de diversos trechos apontados pela variável uso e ocupação do solo como de "Mata de Galeria", de menor propensão ao acúmulo de águas, houve a ocorrência de solos da classe "Hidromórficos Indiscriminados" e baixo grau de declividade, ambos fatores de grande contribuição ao alagamento de áreas.

As áreas apontadas como de média susceptibilidade se apresentaram dispersas, com predominância de ocorrência na porção leste e sul da área estudada. Nestas regiões, houve a classificação quanto ao uso e cobertura como "Urbana 1 - Baixa Densidade", "Campo" e "Cerrado", geralmente associadas a de baixa declividade e/ou baixo acúmulo de fluxo.

Nas áreas de ocorrência dispersa, houve a incidência de características mistas, ora classificadas quanto ao uso e cobertura como "Campo" e "Cerrado" somadas a baixos graus de declividade, ora classificados quanto ao uso e cobertura como "Urbano 3 - Alta Densidade" e "Urbano 2 - Média Densidade" somados ao baixo acúmulo de fluxo de água.

As áreas de baixa susceptibilidade a alagamentos estão associadas à existência de vegetação, conforme classes "Mata de galeria", "Cerrado" e "Reflorestamento" da variável uso e ocupação do solo. Ainda, diversos trechos dos principais corpos d'água da região estudada apresentaram a mesma classificação, visto a soma de dois fatores de baixa contribuição ao fenômeno: existência de mata de galeria e acentuada declividade apontada nas nascentes dos diversos corpos d'água existentes (vide fig. 5).

As consequências decorrentes de alagamentos tendem a ser mais relevantes de acordo com a função do local afetado, logo, foram cruzados os graus de susceptíveis com a variável uso e ocupação do solo, o que resultou no QUADRo IV.

Conforme observado no quadro supracitado, há uma relação direta entre as áreas susceptíveis a alagamentos e as áreas urbanizadas, em especial, aquela da "Urbana 3 - Alta Densidade", tendo sido classificada com de alta susceptibilidade em $26,15 \%$ de toda sua extensão. Essa relação é justificada através do índice de impermeabilização das áreas, que ocorre de maneira acentuada nas áreas com ocupação urbana do que em áreas ocupadas por vegetação, sejam elas de origem natural ou antrópica, acarretando no aumento do escoamento superficial e, por conseguinte, no acúmulo de águas no local.

Outro fenômeno observado no mapa de susceptibilidade é a transição abrupta entre níveis de susceptibilidade em um pequeno espaço territorial. Tal resultado é atribuído à variável uso e ocupação do solo, visto haver um mosaico 
QUADRo IV - Uso e ocupação do solo associado ao grau de susceptibilidade a alagamentos.

TABLE IV - Land use and occupation associated to flooding susceptibility degree.

\begin{tabular}{|l|c|c|c|c|}
\hline \multicolumn{1}{|c|}{ Uso e Ocupação do Solo } & Alta & Baixa & Media & Total geral \\
\hline Mata Galeria & $0,25 \%$ & $6,40 \%$ & $1,23 \%$ & $7,87 \%$ \\
\hline Cerrado / Reflorestamento & $0,12 \%$ & $3,09 \%$ & $1,40 \%$ & $4,61 \%$ \\
\hline Área Urbana 1 - Baixa Densidade/ Agricultura / Campo & $2,62 \%$ & $10,35 \%$ & $27,49 \%$ & $40,45 \%$ \\
\hline Área Urbana 2 - Média Densidade / Solo Exposto & $3,99 \%$ & $0,94 \%$ & $5,32 \%$ & $10,24 \%$ \\
\hline Área Urbana 3 - Alta Densidade / Corpos d' Água & $26,15 \%$ & $0,92 \%$ & $9,74 \%$ & $36,82 \%$ \\
\hline Total geral & $33,13 \%$ & $\mathbf{2 1 , 6 9 \%}$ & $\mathbf{4 5 , 1 8 \%}$ & $100,00 \%$ \\
\hline
\end{tabular}

de áreas com diferentes funções ao longo do trecho estudado, como, por exemplo, a presença da classe "Mata de Galeria" imediatamente ao lado da classe "Urbana 3 Alta Densidade", extremos opostos quanto à contribuição ao fenômeno estudado, por exemplo.

A respeito da variável declividade, com exceção de trechos da área central próximos às nascentes dos rios locais que se apresentaram mais declivosos, há uma tendência geral para que ocorram conformações mais planas ao longo da área de estudo, aumentando a susceptibilidade a alagamentos na maioria dos trechos. Quando se compara este com o mapa de declividade, nota-se uma relação direta entre as áreas de maior susceptibilidade com aquelas de conformação mais planas, especialmente quando associadas à áreas dos centros urbanos.

De forma oposta ao descrito anteriormente, nos extremos norte, sul e leste da unidade hidrográfica há a ocorrência de grandes planícies e que apresentam baixo grau de susceptibilidade. Tal fenômeno se justifica pelo uso e ocupação de tais regiões serem predominantemente associadas à formas de vegetação, nativas ou não.

Já no caso do cruzamento de dados de acúmulo de fluxo de água e de susceptibilidade a alagamento, não é possível notar relação direta entre os mesmos. Segundo o mapa gerado de acúmulo de fluxo de água, a grande maioria da área se encaixa nos graus mínimos de acúmulo de fluxo e decorre da topografia predominantemente plana, o que privilegia a formação de uma lâmina de água, oposta ao comportamento de enxurradas, encontrada em poucos locais da área de estudo.

Ainda relativo à variável acúmulo de fluxo, a mesma é responsável pela criação de pontos dispersos de graus distintos de susceptibilidade a alagamentos, geralmente se traduzindo em polígonos de tamanho pequeno e formando linhas ao longo das áreas. Tal fenômeno é visualizado no núcleo urbano do Guará, por exemplo.

Também, como de forma de validação dos resultados apresentados, foram selecionadas, a título exemplificativo, algumas regiões alagadas na área de estudo. O levantamento realizado por Batista (2014) aponta a predominância de focos de alagamentos e inundações na Asa Norte, região central de Brasília, entretanto, segundo o mesmo, são apontados diversos focos de alagamentos e inundações na área objeto desse estudo, conforme visualizado nas fotos 1 e 2 .

\section{Conclusão}

A metodologia de definição de áreas susceptíveis a alagamentos por meio de SIG, associado ao uso da média ponderada apresentou resultados satisfatórios e coerentes com a realidade.

Também, o modelo de identificação de áreas susceptíveis a alagamento apresentado, ainda que com a definição arbitrária de variáveis ambientais contribuintes
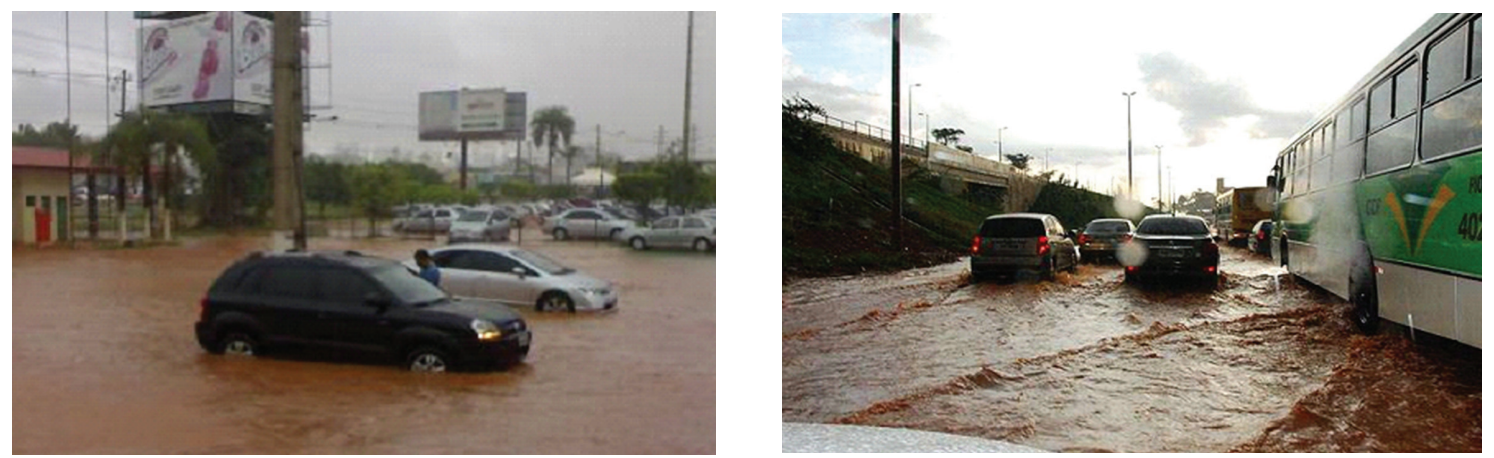

Fot. 1 - (à direita) Pontos de alagamento em estacionamento no Vicente Pires; (à esquerda) Trecho da Estrada Parque Taguatinga - EPTG. Photo 1 - (on the right) Flooding points on parking at the Vicente Pires parking; (on the left) Stretch of Estrada Parque Taguatinga - EPTG. 

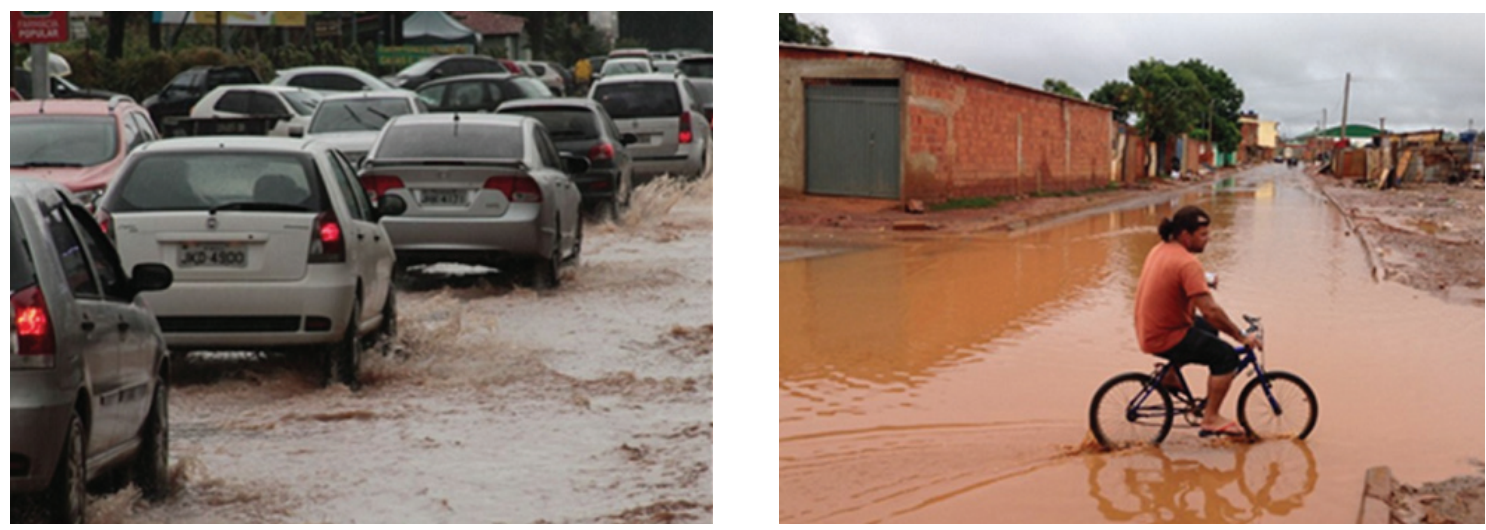

Fot. 2 - Da esquerda para a direita, pontos de alagamento em via no Guará e via alagada na Estrutural.

Photo 2 - Left-to-right, flooding outlets via the Guará and saw flooded in Estrutural.

ao fenômeno e de pesos as suas diversas classes componentes, o que resulta na influência do pesquisador nos resultados, se faz um método útil e prático para a definição de áreas propensas ao fenômeno em pauta.

Por fim, dentre as principais variáveis analisadas, o modelo proposto privilegia o "Uso e Ocupação do Solo" e a "Declividade". Ainda que as demais variáveis sejam importantes ao processo de alagamento, considera-se como essencial a combinação dessas duas variáveis para que haja a ocorrência efetiva do fenômeno estudado.

\section{Referências Bibliográficas}

Adámoli, J., Macêdo, J. e Azevedo, L. G. (1986). Caracterização da região dos cerrados In: Goedert, W. J. ed. Solos dos cerrados: tecnologias e estratégias de manejo. [Planaltina, DF]: EMBRAPA-CPAC / São Paulo: Nobel, p.33-74.

Almeida, L. Q. de. (2012). Riscos ambientais $e$ vulnerabilidades nas cidades brasileiras: conceitos, metodologias e aplicações. São Paulo: Cultura Acadêmica.

Amaral, R.; Ribeiro, R. R. (2009). Inundação e Enchentes. In: Tominaga, L. K.; Santoro, J.; Amaral, R. (Org.) Desastres naturais: conhecer para prevenir. São Paulo: Instituto Geológico.

Barros, J. R. (2003). A chuva no Distrito Federal: o regime $e$ as excepcionalidades do ritmo. 2003. XII, $221 \mathrm{f}$. (Dissertação Mestrado). Univ. Estadual Paulista, Inst. de Geociências e Ciências Exatas.

Batista, P. H. L. (2014). Cartografia geotécnica aplicada aos riscos de alagamento e inundação na bacia do rio São Bartolomeu (Dissertação de Mestrado). Publicação G.DM-236/2014, Departamento de Engenharia Civil e Ambiental, Universidade de Brasília, Brasília, DF, 223 p.
Campana, N. A.; Tucci, C. E. M. (2001). Predicting floods from urban development scenarios: case study of the Diluvio basin, Porto Alegre, Brazil. Urban Water, v. 3. p. 113-124.

Canholl, A.P. (2002). Drenagem urbana e controle de enchentes. São Paulo: Oficina de Textos, 2005, 302 p. TUCCI, C.E.M. - Controle de enchentes. In: Hidrologia Ciência e Aplicação. Porto Alegre: ABRHEditora UFRGS, $3^{\text {a }}$ ed., p. 621-58.

Canholi, A.P. (2005). Drenagem urbana e controle de enchentes. São Paulo: Oficina de Textos, 302 p.

Dias, J. E., Gomes, O. V. O., Rezende, A. S., Salles, R. R. e Góes, M. H. B. (2005). Áreas críticas de erosão do solo no município de Volta Redonda - RJ, Volta Redonda: Caminhos De Geografia - Revista on line.

EMBRAPA - EMPRESA BRASILEIRA DE PESQUISA AGROPECUÁRIA (1979). Serviço Nacional de Levantamento e Conservação de Solos. Súmula 10. Reunião Técnica de Levantamento de Solos. 83p. Miscelânea, 1. Rio de Janeiro. Embrapa - SNLCS.

EMBRAPA - EMPRESA BRASILEIRA E PESQUISA AGROPECUÁRIA (1978). Serviço Nacional de Levantamento de Solos. Levantamento de reconhecimento dos solos do Distrito Federal. Rio de Janeiro, Embrapa-SNLCS.

EMBRAPA - EMPRESA BRASILEIRA E PESQUISA AGROPECUÁRIA (2004). Mapa Pedológico Digital - SIG Atualizado do Distrito Federal Escala 1:100.000 e uma Síntese do Texto Explicativo. Documentos Embrapa Cerrados.

EMBRAPA - EMPRESA BRASILEIRA E PESQUISA AGROPECUÁRIA (2006). Centro Nacional de Pesquisas de Solos. Sistema brasileiro de classificação de solos. Brasília, Embrapa - Produção de Informação.

Fonseca, F. O. (org.). (1999). Olhares sobre o lago Paranoá. Brasília. Secretaria de Meio Ambiente e Recursos Hídricos do Distrito Federal - SEMARH. 
Freitas-Silva, F. H. \& Campos, J. E. G. (1998). Geologia do Distrito Federal. In: Campos, J. E. G. \& FreitasSilva, F. H., coords. Inventário hidrogeológico e dos recursos hídricos superficiais do Distrito Federal. Brasília, SEMATEC: IEMA: MMA-SRH, CD ROM.

GOVERNO DO DISTRITO FEDERAL (GDF) (2010). Mapa índice articulação SICAD 1:10.000 - SIRGAS. Secretaria de Habitação, Regularização e Desenvolvimento Urbano (SEDHAB/DF), Brasília, DF, Escala 1:10.000. Formato Digital.

INMET - INSTITUTO NACIONAL DE METEOROLOGIA (1992). Normas Climatológicas (1961-1990). Brasília, INMET - Instituto Nacional de Meteorologia/Ministério da Agricultura e Reforma Agrária, 1992.

Jacob, A. C. P. (2014) Você sabe qual a diferença entre alagamento e inundação? Rio de Janeiro:[S.l.], 2014. Disponível em: http://aquafluxus.com.br/. Acesso em: 30 abril de 2015.

Martins, E. S., Reatto, A., Carvalho Junior, O. A. e Guima-rães R. F. (2004b). Evolução Geomorfológica do Distrito Federal. Documentos. Embrapa Cerrados. Planaltina, DF.

Menezes, P. H. B. J., Roig, H. L., Almeida, T. Soares Neto, G. B. e Isaías, F. B. (2012). Análise da evolução do padrão de uso e ocupação do solo na bacia de contribuição do Lago Paranoá - DF. UNESP - Campus de Rio Claro - IGCE.
Muller, C. R. (2012). Avaliação de susceptibilidade à inundações utilizando geotecnologias para a bacia hidrográfica do rio Cachoeira, Joinville/SC (Dissertação Mestrado Profissional em Planejamento Territorial e Desenvolvimento Socioambiental). Universidade do Estado de Santa Catarina, Florianópolis.

Novaes Pinto, M. (1994). Caracterização geomorfológica do Distrito Federal. In: Novaes Pinto, M., org. Cerrado: Caracterização, ocupação e perspec-tivas. Brasília, Universidade de Brasília/SEMATEC, p.285-344.

Oliveira, L. M. de (2010). Acidentes Geológicos Urbanos. Curitiba: MINEROPAR - Serviço Geológico do Paraná.

Resende, M., Curi, N. L., Santana, D. P. (1988). Pedologia e fertilidade do solo: interações e aplicações. Brasília: Ministério da Educação/Lavras: ESAL/ Piracicaba: POTAFOS, 83p.

Salomão, F. X. T. \& Antunes F. S. (1998). Solos. In: Oliveira, A. M. S. \& Brito, S. N. A. Geologia de Engenharia. São Paulo, SP, Associação Brasileira de Geologia de Engenharia (ABGE).

Sausen, T. M.; Lacruz, M. S. P. (2015) Sensoriamento Remo para Desastres. São Paulo: Oficina de Textos, $288 \mathrm{p}$. 